\title{
Assessing road effects on bats: the role of landscape, road features, and bat activity on road-kills
}

Received: 16 May 2012/ Accepted: 20 November 2012/Published online: 13 December 2012

(C) The Ecological Society of Japan 2012

\begin{abstract}
Recent studies suggest that roads can significantly impact bat populations. Though bats are one of the most threatened groups of European vertebrates, studies aiming to quantify bat mortality and determine the main factors driving it remain scarce. Between March 16 and October 31 of 2009 , we surveyed road-killed bats daily along a $51-\mathrm{km}$-long transect that incorporates different types of roads in southern Portugal. We found 154 road-killed bats of 11 species. The two most common species in the study area, Pipistrellus kuhlii and P. pygmaeus, were also the most commonly identified road-kill, representing $72 \%$ of the total specimens collected. About two-thirds of the total mortality occurred between mid July and late September, peaking in the second half of August. We also recorded casualties of threatened and rare species, including Miniopterus schreibersii, Rhinolophus ferrumequinum, $R$. hipposideros, Barbastella barbastellus, and Nyctalus leisleri. These species were found mostly in early autumn, corresponding to the mating and swarming periods. Landscape features were the most important variable subset for explaining bat casualties. Road stretches crossing or in the vicinity of high-quality habitats for bats-including dense Mediterranean
\end{abstract}

Electronic supplementary material The online version of this article (doi:10.1007/s11284-012-1009-6) contains supplementary material, which is available to authorized users.

D. Medinas $(\bowtie) \cdot$ J. T. Marques · A. Mira

Conservation Biology Unit, Department of Biology, University

of Évora, Núcleo da Mitra, 7002-554 Évora, Portugal

E-mail: denimedinas@gmail.com

Tel.: + 351-266-740800

D. Medinas · A. Mira

CIBIO-Research Center in Biodiversity and Genetic Resources, University of Évora, Évora, Portugal

D. Medinas $\cdot$ A. Mira

ICAAM-Institute of Mediterranean Agrarian and Environmental Sciences, University of Evora, Evora, Portugal

J. T. Marques

CBA-Centro de Biologia Ambiental, Faculdade de Ciências da Universidade de Lisboa, 1700 Lisbon, Portugal woodland ("montado") areas, water courses with riparian gallery, and water reservoirs-yielded a significantly higher number of casualties. Additionally, more roadkilled bats were recorded on high-traffic road stretches with viaducts, in areas of higher bat activity and near known roosts.

Keywords Road-kill modeling - Mediterranean landscape $\cdot$ Bat activity $\cdot$ Phenology $\cdot$ Road traffic

\section{Introduction}

Roads are a widespread and an increasingly present feature in modern landscapes (Giulio et al. 2009). They improve human communications and play an important social role in the present-day societies (Trombulak and Frissell 2000; Hawbaker et al. 2004), but they are also a major driving factor of biodiversity loss worldwide (Giulio et al. 2009; Lopez 2009). Overall, the presence of roads is highly correlated with changes in: species composition (Forman and Alexander 1998), population size (Fahrig and Rytwinski 2009; Lopez 2009), reproductive success (Trombulak and Frissell 2000), behavioral responses (Jaeger et al. 2005), and physiological condition of animals (Coffin 2007). Roads can also act as barriers or filters to animal movement during foraging and dispersal, leading to changes in home range size and shape (Clevenger et al. 2003). On a local scale, animal populations may be prevented from accessing a formerly used habitat by roads, which can lead to population declines (Eigenbrod et al. 2008; Clark et al. 2010). These isolation effects may be stronger than expected since even small and recently constructed roads can exert a significant impact upon the population genetic structure of some species (Clark et al. 2010). However, the most immediate and evident effect of roads on wildlife is the mortality of individuals caused by collisions with vehicles, with particular importance for species with large home ranges (Forman and Alexander 1998; Ascensão and Mira 2007). 